\title{
MITTEILUNGEN
}

\section{Henry-E.-Sigerist-Preis 1969}

(Dr.-Markus-Guggenheim-Schnurr-Stiftung für Geschichte der Medizin und der Naturwissenschaften)

Der Jury sind acht medizingeschichtliche Dissertationen des Jahres 1968 eingereicht worden (Universität Basel 1, Universität Zürich 7). Sie zeigen, daß zum mindesten an zwei der fünf medizinischen Fakultäten der Schweiz - auch die jüngste Generation sich rege an der historischen Erforschung ihres Faches beteiligt. Im Vordergrund des Interesses scheint dabei die Geschichte der Psychiatrie zu stehen; ihr sind vier der acht Arbeiten gewidmet.

Wir möchten daraus namentlich die glänzend geschriebene Studie von JEan-Marie Brutrin (Zürich) hervorheben, der unter dem Titel Différentes théories sür l'hystérie dans la première moitié $d u X I X^{e}$ siècle, die heute weniger bekannten, für die Entwicklung des medizinischen Denkens jedoch wichtigen Auffassungen von Georget, Landouzy und Briquet vergleicht. Mit einigem Erstaunen erfährt der Leser, daß die Theorien der uterinen Genese der Hysterie noch im 19. Jahrhundert in Marc-Hector Landouzy einen überzeugten Verfechter fand.

Der Preis im Betrag von 500 Franken wurde jedoch Hans Peter SchönWETtER (Universität Zürich) für seine Dissertation Zur Vorgeschichte der Endokrinologie (Juris-Verlag, Zürich 1968, 70 Seiten) zugesprochen und anläßlich der Jahrestagung der SGGMN in St.Gallen überreicht. Im ersten, allgemeinen Teil zeigt der Autor, wie sich seit dem 17.Jahrhundert in kleinen Schritten die Erkenntnis Bahn brach, daß es Drüsen ohne Ausfuhrgänge gibt, die demnach ihre zunächst unbekannten - Sekrete unmittelbar ins Blut abgeben müssen. Selbst die Anatomie dieser Drüsen war freilich lange nur mangelhaft bekannt, und hinsichtlich der Funktion berrschten noch in der 2. Hälfte des 19. Jahrhundert kühne Spekulationen vor, die im Rückblick zum Teil recht abstrus erscheinen, für die Zeitgenossen jedoch durchaus erwägenswert waren. Dies erfährt man vor allem aus dem speziellen Teil, in dem die einzelnen Drüsen besprochen werden.

Mit den Experimenten, in denen A.A. Berthold 1849 die innere Sekretion des Hodens nachwies, läßt Schönwetter die eigentliche Geschichte der Endokrinologie beginnen und die Vorgeschichte enden. Bei anderen Drüsen blieb die endokrine Funktion länger ungewiß; die Entwicklung wird in diesen Fällen mit Recht über die Zeitmarke 1849 hinaus weiterverfolgt.

Der Autor hat in seiner Dissertation ein reiches Quellenmaterial verarbeitet. Seine Begeisterung für das Thema wird bis in die sprachlichen Formulierungen hinein spürbar. Schönwetters Monographie trägt wesentlich zum historischen Verständnis eines heute sehr wichtigen Teilgebietes der Medizin bei. 